

\section{Mechanisms employed by cellulase systems to gain access through the complex architecture of lignocellulosic substrates}

Bryon S. Donohoe*

National Renewable Energy Laboratory

Biosciences Center

15013 Denver West Parkway

Golden, CO 80401

bryon.donohoe@nrel.gov

Phone: (303) $384-7773$

Michael G. Resch

National Renewable Energy Laboratory

National Bioenergy Center

15013 Denver West Parkway

Golden, CO 80401

michael.resch@nrel.gov 


\begin{abstract}
To improve the deconstruction of biomass, the most abundant terrestrial source of carbon polymers, en route to renewable fuels, chemicals, and materials more knowledge is needed into the mechanistic interplay between thermochemical pretreatment and enzymatic hydrolysis. In this review we highlight recent progress in advanced imaging techniques that have been used to elucidate the effects of thermochemical pretreatment on plant cell walls across a range of spatial scales and the relationship between the substrate structure and the function of various glycoside hydrolase components. The details of substrate and enzyme interactions are not yet fully understood and the challenges of characterizing plant cell wall architecture, how it dictates recalcitrance, and how it relates to enzyme-substrate interactions is the focus for many research groups in the field. Better understanding of how to match pretreatments with improved enzyme mixtures will lead to lower costs for industrial biorefining.
\end{abstract}

\title{
Introduction
}

The most abundant form of terrestrial carbon is in the form of plant biomass. Developing technolgies to convert plant cell wall carbohydrates and lignin to fuels and chemicals will aid in reducing carbon dioxide in the atmosphere, dependence on oil importation, and improve energy independence. A deep understanding of the effects of thermochemical pretreatment and saccharification mechanisms will enable improvement of enzyme saccharification of biomass essential to the development of economically sustainable biorefineries.

Enzymatic hydrolysis, in which lignocellulosic biomass is converted into fermentable sugars may be the most complex step in biomass conversion. At the molecular scale, the hydrolysis mechanisms of glycoside hydrolases have been extensively characterized and recently reviewed by Payne et al. [1]. However, the complex nature of the plant cell wall presents many factors that impede enzymes such as substrate accessibility, lignin interference, cellulose crystallinity, and product inhibition. Nonetheless, enzymatic hydrolysis for biomass deconstruction offers the potential of high yields at mild operating conditions and higher selectivity than those of purely thermochemical processes. From the macromolecular scale through the cellular scale, we are only beginning to understand how a combination of enzymes, with a range of specificities, work together to gain and maintain access to complex lignocellulosic substrates. In this review we highlight recent progress to elucidate the enzymatic cell wall deconstruction mechanisms with emphasis on visualization techniques to understand the relationship between cell wall architecture and the function of Carbohydrate Active enzyme (CAZyme) components [2].

\section{Direct substrate characterization}

Determining what changes enzymes have made to lignocellulosic substrates relies on a foundation of knowledge about cell wall architecture that has benefited from new developments in imaging technologies along with careful consideration of sample preparation techniques (Figure 1). The direct observation of partially digested substrates has provided important new insights, across a range of scales, into biomass deconstruction and can be used elucidate cellulose mechanisms [3-7].

One of the most widely accessible techniques for substrate visualization is fluorescence microscopy. In comparison to other techniques, fluorescence imaging is fast, sensitive, and can be used for time-resolved imaging. Possibly the most informative use of fluorescence microscopy is im- 
muno-fluorescence imaging using monoclonal antibodies to identify plant cell wall polysaccharides. This has been shown to be effective in characterizing plant cell walls before and after deconstruction $[3,8]$. Confocal microscopy was even used to guide the development of kinetic models that could suggest improvements in cellulase cocktails by revealing mechanisms and rate-limiting steps during cellulose degradation [9]. The results suggested that exposing new enzyme binding sites is a crucial rate-limiting step.

The only real disadvantage of fluorescence microscopy for addressing critical questions in biomass conversion is its lateral resolution is diffraction limited to roughly $250 \mathrm{~nm}$. This is sufficient to visualize major cell wall layers and detect enzymes, but insufficient to monitor single enzymes or interrogate cell wall architecture. Super-resolution techniques however, have been in development over the past several years, achieve lateral resolution down to tens of nanometers, are now becoming commercially available and more widely used. These techniques use specialized illumination schemes, non-linear fluorophore responses, and image processing based localization to achieve stunning results. Super-resolution was used to measure the binding and movement of individual Cel7A CBH enzymes on cellulose surfaces and document their stopand-go progression [7]. These new techniques are only beginning to be applied to plant samples, like the recent demonstration of super-resolution imaging to visualize cellulose bundles in onion epidermis cell walls [10]. Fluorescence techniques benefit from the continual development of fluorescent probes for investigating plant cell wall architecture and deconstruction and were reviewed recently by Paes [11]. Among the developments highlighted is photoactivatable fluorescent-labeled proteins fused to cellulase enzymes or CBMs to improve the resolution of localization and dynamics studies down to $10-50 \mathrm{~nm}$ [12].

In another recent review of biomass imaging, Bubner et al point out the advantages that atomic force microscopy (AFM) has in terms of high resolution and being able to perform imaging on fully hydrated samples [13]. This is clearly true for imaging cellulose model substrates; however imaging real plant cell wall substrates still requires extensive and careful sample preparation that is sometimes discounted. Even for studies on model substrates, attention to minimal modification, and immobilization onto a surface are required for high-quality, interpretable data [4]. A recent study developed a simple and gentle protocol for cell wall preparation for AFM imaging of microfibrils and cell wall matrix materials at the inner surface of the epidermal cell walls in Arabidopsis [14]. With these techniques, microfibrils were made clearly visible in a near native state. A striking observation was that no obvious cross-links were seen among microfibrils. Instead, the microfibrils simply appear to come into close proximity with one another over distances of several tens of nanometers

Another advance imaging technique used to reveal the complex 3D architecture of plant cell walls is electron tomography [15]. Sakar et al compared tradition chemical fixation, highpressure freezing followed by freeze substitution and resin embedding (HPF-FS), and vitreous sectioning methods to preserve plant tissues and detect structural differences in plants with genetically altered cell walls. Their study provides a novel view into the complexity of the cell wall, and they conclude that cryopreservation provides closest-to-native preservation. Electron tomography was also used as the primary tool to study the 3D nanoscale architecture of pretreated biomass [16]. This study went beyond traditional segmentation of tomography data sets and extracted mathematical representations for the nanoscale geometry of cellulose microfibrils in the pretreated biomass. The models were used to calculate microfibril curvature and suggested 
that microfibrils twist to accommodate curvature. There remains room to improve the quantitative image analysis tools necessary to segment and model hemicelluloses and lignin along with the cellulose microfibrils.

\section{New insights into the impact of pretreatment on plant cell wall archi- tecture}

A conceptual model of plant cell walls is that of a fiber reinforced matrix composed of a meshwork of cellulose microfibrils embedded in a matrix of hemicellulose and lignin polymers. Plants have evolved to resist environmental stressors such as microbial infection and drought, which has naturally selected cell walls that are recalcitrant. Thermochemical pretreatments typically increase the accessibility of cellulose microfibrils to cellulase enzymes by disruption and removal of either the hemicellulose or the lignin component from the plant cell wall. However, pretreatment can go too far, and a thorough study of the effect of remaining lignin content on dilute acid pretreated poplar suggested that partial (leaving up to $60 \%$ of the lignin in place) rather that complete delignification may be better to maximize glucose yields [17]. Similarly, the accessibility and digestibility gains made during an initial alkali pretreatment can be partially undone by a secondary acidic conditioning step by causing precipitation of solubilized compounds on cell wall surfaces [18]. These observations fit well with a concept of lignin as both a barrier and a spacer among cellulose microfibrils. Water has also been shown to be a crucial spacer between individual microfibrils within larger macrofibrils. This entrained water can be driven out during severe thermochemical pretreatment, leading to an increase in microfibril crystallinity and diameter [19].

Several recent studies have shown that improvement in hydrolysis rates where achieved when extensive mechanical disruption complements chemical deconstruction during pretreatment [2023]. During enzymatic digestion wide-angle $x$-ray diffraction (WAXD) analysis indicated that non-crystalline cellulose was not preferentially degraded, consistent with a model of cellulose microfibrils with widely distributed disorder and defects rather than discreet amorphous cellulose domains. Thygesen et al use a model based on mechanical principles to account for the interaction between the mechanical forces of mixing and agitation within a reactor and the hydrolysis of glycosidic bonds by enzymes to weaken cell walls [24]. These recent studies among others have identified lignin removal and cellulose crystallinity as the major pretreatment barriers to successively overcome to improve hydrolysis by cellulases [25-27].

\section{The enigmatic inhibition of cellulases by lignin}

The inhibitory effect of lignin on enzymatic hydrolysis has been hypothesized to be the result of decreased accessibility caused by steric hindrance, by nonspecific binding, and small molecule inhibition (Figure 2) [28]. Some thermochemical pretreatments remove much of the cell wall lignin while others simply cause lignin to coalesce and migrate through the plant cell walls [3,29]. Not surprisingly, lignin droplets deposited on the surface of otherwise lignin free model cellulose (Avicel) retard enzymatic hydrolysis initially. However, that inhibition abates as the hydrolysis continues until it was undetectable at high cellulose conversions [30]. The authors concluded that nonspecific binding of enzymes to lignin droplets was not the primary mechanism for the cellulase inhibition. Instead, physical surface blockage of cellulose by lignin droplets was proposed to be responsible. 
Another recent investigation concluded that differences in lignin properties dictated their enzyme adsorption capacity [31]. They compared enzyme adsorptions onto lignins from six different feedstocks. The lignins displayed decreasing enzyme adsorption capacity in the order of pine lignin > corn stover lignin > aspen lignin > kenaf lignin. The authors suggest that lignin composition (S/G ratio) and structural features, such as carboxylic acid, aliphatic hydroxyl, and phenolic hydroxyl side groups dictate their capacity to bind cellulases. The adsorption capacity of single component enzymes onto lignin substrates decreased in the order beta-glucosidases > endoglucanases $>$ xylanases $>$ cellobiohydrolases, which may be correlated to protein surface hydrophobicity [32,33]. Still other studies have demonstrated a temperature and $\mathrm{pH}$ dependence on the impact of non-specific binding of cellulases to lignin [34,35].

There have been several reports over the years of additives that could be used as blocking agents to lessen the effect of non-productive enzyme binding including bovine serum albumin and detergents [36]. A recent example of this approach is the use of sodium lignosulfonate or polyethylene glycol [37,38]. Lignosulfonates and linear anionic aromatic polymers blocked nonproductive cellulase adsorption onto lignin, but also reduced cellulase adsorption on cellulose. It is unclear if adding these chemicals in an industrial setting would be cost effective. To account for the phenomenon of declining reaction rates Newman et al developed a mathematical model of the inhibitory effect of lignin on enzymatic hydrolysis [39]. Using three parameters (blocked cellulose, enzyme loading, and a mechanism index) and with cellulose accessibility remaining constant during the enzymatic conversion they concluded that declining reaction rates are attributed to enzyme deactivation caused by non-productive binding.

\section{Enzyme binding dynamics and the role of CBMs}

Understanding substrate recognition and binding specificity to enable cell wall deconstruction are essential to a broader understanding of cellulase action. How cellulose binding modules (CBMs) aid cellulases in penetrating the bulk of biomass particles depends on their size, concentration, and binding equilibrium. Computational simulation of CBM binding dynamics demonstrates that the flat surface of CBMs preferentially bind the hydrophobic face of cellulose [40]. Theory and experimentation were recently used to study the dynamic equilibrium of adsorption and desorption kinetics for the Hypocrea jecorina cellulases Cel7A, Cel6A, and Cel7B determine binding reversibility [41]. The results suggested that for short enzyme substrate contact times and at moderate enzyme and substrate loadings, the systems are in dynamic equilibrium and that simple equilibrium reaction schemes and kinetic models are sufficient to describe the systems under these conditions. However, how these results can be applied to the high enzyme and substrate loadings in an industrial setting is still unclear. A fluorescent model substrate was used to determine that at low enzyme concentrations a single binding site model fit the data well, even though at higher enzyme loadings non-productive binding shifted the results to favor a model with more than a one binding site [42].

Adding or deleting a CBM has different effects when paired with different catalytic domains and is highly dependent on whether enzymatic activity is measured on insoluble or soluble substrates. Fusing a CBM onto Ce19A or Cel5A catalytic domains enhanced their activity on insoluble lignocellulosic substrates by up to three fold [43]. Meanwhile, the opposite effect has been shown for enzymes tested on soluble substrates. Post-translational glycosylation of the CBM and linker region have been shown to aid substrate binding, protein stability and protease resistance [44,45], indicating crucial roles for these protein modifications. 


\section{Synergy among cellulases and the role of accessory enzymes}

The free enzyme cocktail of carbohydrate active enzymes (CAZymes) found in commercial preparations is based on the H. jecorina secretome and consists of separate proteins ranging in size from 20-100 kDa with individual catalytic and binding specificities [2]. Synergistic activity among different enzymes is required for efficient saccharification of cellulose alone and becomes even more crucial for the multiple complex polysaccharides in plant cell walls. Possibly the simplest and most common view of synergistic cellulase mechanisms is the teamwork between endoglucanases (EGs) creating new cellulose chain ends along a microfibil surface and cellobiohydrolases (CBHs) doing the heavy lifting of cellulose depolymerization by chain end specific processive hydrolysis [1] (Figure 3). In a study of bacterial cellulose hydrolysis by CBH Cel7A and EG Cel5A from $H$. jecorina, Jalik et al found that at optimal enzyme/substrate ratios, the overall rate of hydrolysis was limited by the rate of processivity [46]. From this, they proposed a mechanism of endo-exo synergism where the primary role of EG is to remove amorphous cellulose regions that would otherwise cause the processive $\mathrm{CBH}$ to stall.

In a recent compelling study, the authors used in-situ, time-lapse AFM to monitor the degradation of bacterial cellulose fibers by three cellulolytic enzymes, Cel6A, Cel7A, and Cel7B, from $H$. jecorina [47]. Each of these three enzymes are incapable of substantial cellulose hydrolysis alone, however, mixtures of any two of the enzymes exhibit synergistic effects. A novel finding was that the degree of synergism depended on order that the enzymes were added to the substrate. For example, adding Cel7A to cellulose that had been previously digested by Cel7B enhanced reaction rates and increased extent of hydrolysis, whereas adding enzymes in the opposite order was not effective.

An important development in the field of cellulase research in the past several years has been the discovery and understanding of the lytic polysaccharide monooxygenase (LPMO) family of enzymes. LPMOs (AA9, formerly GH61) utilize a copper cofactor, carry out oxidative cleavage on cell wall polymers, and are synergistic with glycoside hydrolases on several different lignocellulosic substrates [48-50]. Although AA9 clearly acts synergistically with hydrolytic cellulases and increases cellulose deconstruction and have been shown to increase glucan release by 5-25\%, the degree of enhancement is dependent on substrate properties. The benefit of AA9 synergy was not seen with some substrates including amorphous cellulose substrates or cellulose II and III polymorphs [51].

\section{Multi-domain enzymes and complexed cellulosomes}

In contrast to the free enzyme systems, cellulosomal complexes are large extracellular enzyme complexes composed of multiple enzymes with different binding and substrate specificities all bound to a unifying scaffoldin protein [52]. Cellulosomes are produced by mesophilic anaerobic bacteria members of Clostridium, Acetivibrio, Bacteroides, and Ruminococcus. Examples from both the free and complexed enzyme systems are among the leading candidates for industrialscale biochemical deconstruction of lignocellulosic feedstocks [53].

Free enzymes operate by an ablative, surface limited mechanism, while cellulosomes appear to be able to physically parse cellulose microfibrils away from larger bundles to increase accessibility as they work [5,54]. When the two enzyme systems are combined, these compatible mechanisms are synergistic [5] (Figure 4). Key differences in the deconstruction mechanisms between these two enzyme systems were demonstrated on model cellulose and pretreated biomass subs- 
tates. When free enzymes are combined with clean fractionation pretreated biomass, they are able to gain access to cell wall surfaces and digest loose exposed microfibrils. In contrast, when clean fractionation pretreated biomass was incubated with cellulosomes, the surface of the cell walls displayed raised pockets of delamination. Interestingly, combining these two deconstruction mechanisms synergistically enhances the glucan and xylan hydrolysis by a combination of ablated cell wall surfaces and pocket-type delaminations, with channels penetrating into the cell wall. Presumably, these mutually beneficial mechanisms aid in physical and chemical deconstruction, where large complexed enzymes expose more reactive surface area to allow for the processive hydrolysis action by free fungal enzymes [26]. Insight into the different mechanisms underlying these two polysaccharide deconstruction paradigms should enable new combined strategies for enzyme engineering to overcome biomass recalcitrance.

\section{Concluding remarks}

With the motivation of producing fuels and chemicals from biomass in a sustainable manner researchers have advanced the understanding of complex enzyme and substrate interactions. Hydrothermal pretreatment and mechanical disruption of biomass aimed at removing or at least redistributing lignin and perturbing cellulose crystallinity has enabled more efficient enzymatic hydrolysis at the bench scale. However, preserving the cell wall carbohydrates and maximizing carbon utilization is a strong technoeconomic driver for an industrial process.

New advances and novel application of imaging techniques combined with expanding labeling tools and careful sample preparation has enabled direct visualization of enzymatic deconstruction at relevant scales and provided new insights into mechanisms employed by cellulose systems. Improved understanding of the different and often complementary cellulase mechanisms should enable new combined strategies for enzyme engineering to overcome biomass recalcitrance. Once efficient saccharification has been established the conversion of sugars and lignin into competitively priced fuels and higher value chemicals will drive the commercial application.

\section{Acknowledgements}

The authors acknowledge funding support from the U.S. Department of Energy (DOE) Office of Science, Office of Biological and Environmental Research through the BioEnergy Science Center (BESC), a DOE Bioenergy Research Center and the DOE Office of Energy Efficiency and Renewable Energy, Bioenergy Technologies Office under Contract No. DE-AC3608GO28308DOE with the National Renewable Energy Laboratory. 


\section{Bibliography}

**1. Payne CM, Knott BC, Mayes HB, Hansson H, Himmel ME, Sandgren M, Stahlberg J, Beckham GT: Fungal Cellulases. Chemical Reviews 2015, 115:1308-1448.

2. Lombard V, Ramulu HG, Drula E, Coutinho PM, Henrissat B: The carbohydrateactive enzymes database (CAZy) in 2013. Nucleic Acids Research 2014, 42:D490-D495.

3. Chundawat SPS, Donohoe BS, Sousa LD, Elder T, Agarwal UP, Lu FC, Ralph J, Himmel ME, Balan V, Dale BE: Multi-scale visualization and characterization of lignocellulosic plant cell wall deconstruction during thermochemical pretreatment. Energy \& Environmental Science 2011, 4:973-984.

4. Jeoh T, Santa-Maria MC, O'Dell PJ: Assessing cellulose microfibrillar structure changes due to cellulase action. Carbohydrate Polymers 2013, 97:581-586.

5. Resch MG, Donohoe BS, Baker JO, Decker SR, Bayer EA, Beckham GT, Himmel $M E$ : Fungal cellulases and complexed cellulosomal enzymes exhibit synergistic mechanisms in cellulose deconstruction. Energy \& Environmental Science 2013, 6:1858-1867.

6. Brunecky R, Alahuhta M, Xu Q, Donohoe BS, Crowley MF, Kataeva IA, Yang S-J, Resch MG, Adams MWW, Lunin VV, et al.: Revealing Nature's Cellulase Diversity: The Digestion Mechanism of Caldicellulosiruptor bescii CelA. Science 2013, 342:1513-1516.

7. Jung J, Sethi A, Gaiotto T, Han JJ, Jeoh T, Gnanakaran S, Goodwin PM: Binding and Movement of Individual Cel7A Cellobiohydrolases on Crystalline Cellulose Surfaces Revealed by Single-molecule Fluorescence Imaging. Journal of Biological Chemistry 2013, 288:24164-24172.

8. DeMartini JD, Pattathil S, Avci U, Szekalski K, Mazumder K, Hahn MG, Wyman CE: Application of monoclonal antibodies to investigate plant cell wall deconstruction for biofuels production. Energy \& Environmental Science 2011, 4:4332-4339.

9. Luterbacher JS, Walker LP, Moran-Mirabal JM: Observing and modeling BMCC degradation by commercial cellulase cocktails with fluorescently labeled Trichoderma reseii Cel7A through confocal microscopy. Biotechnology and Bioengineering 2013, 110:108-117.

10. Liesche J, Ziomkiewicz I, Schulz A: Super-resolution imaging with Pontamine Fast Scarlet 4BS enables direct visualization of cellulose orientation and cell connection architecture in onion epidermis cells. Bmc Plant Biology 2013, 13.

11. Paes G: Fluorescent Probes for Exploring Plant Cell Wall Deconstruction: A Review. Molecules 2014, 19:9380-9402.

12. Fox JM, Jess P, Jambusaria RB, Moo GM, Liphardt J, Clark DS, Blanch HW: A single-molecule analysis reveals morphological targets for cellulase synergy. Nature Chemical Biology 2013, 9:356-+.

13. Bubner P, Plank H, Nidetzky B: Visualizing cellulase activity. Biotechnology and Bioengineering 2013, 110:1529-1549. 
14. Zhang T, Mahgsoudy-Louyeh S, Tittmann B, Cosgrove DJ: Visualization of the nanoscale pattern of recently-deposited cellulose microfibrils and matrix materials in never-dried primary walls of the onion epidermis. Cellulose 2014, 21:853-862.

15. Sarkar P, Bosneaga E, Yap EG, Das J, Tsai WT, Cabal A, Neuhaus E, Maji D, Kumar S, Joo M, et al.: Electron Tomography of Cryo-Immobilized Plant Tissue: A Novel Approach to Studying 3D Macromolecular Architecture of Mature Plant Cell Walls In Situ. Plos One 2014, 9:16.

16. Ciesielski PN, Matthews JF, Tucker MP, Beckham GT, Crowley MF, Himmel ME, Donohoe BS: 3D Electron Tomography of Pretreated Biomass Informs Atomic Modeling of Cellulose Microfibrils. ACS nano 2013.

17. Sun QN, Foston M, Meng XZ, Sawada D, Pingali SV, O'Neill HM, Li HJ, Wyman CE, Langan $P$, Ragauskas AJ, et al.: Effect of lignin content on changes occurring in poplar cellulose ultrastructure during dilute acid pretreatment. Biotechnology for Biofuels 2014, 7.

18. Karuna N, Zhang L, Walton JH, Couturier M, Oztop MH, Master ER, McCarthy MJ, Jeoh T: The impact of alkali pretreatment and post-pretreatment conditioning on the surface properties of rice straw affecting cellulose accessibility to cellulases. Bioresource Technology 2014, 167:232-240.

19. Langan P, Petridis L, O'Neill HM, Pingali SV, Foston M, Nishiyama Y, Schulz R, Lindner B, Hanson BL, Harton S, et al.: Common processes drive the thermochemical pretreatment of lignocellulosic biomass. Green Chemistry 2014, 16:63-68.

20. Chen XW, Shekiro J, Pschorn T, Sabourin M, Tao L, Elander R, Park S, Jennings E, Nelson $\mathrm{R}$, Trass $\mathrm{O}$, et al.: A highly efficient dilute alkali deacetylation and mechanical (disc) refining process for the conversion of renewable biomass to lower cost sugars. Biotechnology for Biofuels 2014, 7.

21. Ibbett R, Gaddipati S, Hill S, Tucker G: Structural reorganisation of cellulose fibrils in hydrothermally deconstructed lignocellulosic biomass and relationships with enzyme digestibility. Biotechnology for Biofuels 2013, 6:15.

22. Hall M, Bansal P, Lee JH, Realff MJ, Bommarius AS: Cellulose crystallinity - a key predictor of the enzymatic hydrolysis rate. Febs Journal 2010, 277:15711582.

23. Lee DS, Wi SG, Lee SJ, Lee YG, Kim YS, Bae HJ: Rapid saccharification for production of cellulosic biofuels. Bioresource Technology 2014, 158:239-247.

24. Thygesen LG, Thybring EE, Johansen KS, Felby C: The Mechanisms of Plant Cell Wall Deconstruction during Enzymatic Hydrolysis. Plos One 2014, 9:4.

25. Meng XZ, Ragauskas AJ: Recent advances in understanding the role of cellulose accessibility in enzymatic hydrolysis of lignocellulosic substrates. Current Opinion in Biotechnology 2014, 27:150-158.

26. Resch MG, Donohoe BS, Ciesielski PN, Nill JE, Magnusson L, Himmel ME, Mittal A, Katahira R, Biddy MJ, Beckham GT: Clean Fractionation Pretreatment Reduces Enzyme Loadings for Biomass Saccharification and Reveals the Mechanism of Free and Cellulosomal Enzyme Synergy. Acs Sustainable Chemistry \& Engineering 2014, 2:1377-1387. 
27. Karp EM, Donohoe BS, O'Brien MH, Ciesielski PN, Mittal A, Biddy MJ, Beckham GT: Alkaline Pretreatment of Corn Stover: Bench-Scale Fractionation and Stream Characterization. Acs Sustainable Chemistry \& Engineering 2014, 2:1481-1491.

28. Zeng YN, Zhao S, Yang SH, Ding SY: Lignin plays a negative role in the biochemical process for producing lignocellulosic biofuels. Current Opinion in Biotechnology 2014, 27:38-45.

29. Donohoe BS, Decker SR, Tucker MP, Himmel ME, Vinzant TB: Visualizing lignin coalescence and migration through maize cell walls following thermochemical pretreatment. Biotechnol Bioeng 2008, 101:913-925.

30. Li HJ, Pu YQ, Kumar R, Ragauskas AJ, Wyman CE: Investigation of Lignin Deposition on Cellulose During Hydrothermal Pretreatment, Its Effect on Cellulose Hydrolysis, and Underlying Mechanisms. Biotechnology and Bioengineering 2014, 111:485-492.

31. Guo FF, Shi WJ, Sun W, Li XZ, Wang FF, Zhao J, Qu YB: Differences in the adsorption of enzymes onto lignins from diverse types of lignocellulosic biomass and the underlying mechanism. Biotechnology for Biofuels 2014, 7.

32. Sammond DW, Yarbrough JM, Mansfield E, Bomble YJ, Hobdey SE, Decker SR, Taylor LE, Resch MG, Bozell JJ, Himmel ME, et al.: Predicting Enzyme Adsorption to Lignin Films by Calculating Enzyme Surface Hydrophobicity. Journal of Biological Chemistry 2014, 289:20960-20969.

33. Haven $\mathrm{MO}$, Jorgensen $\mathrm{H}$ : Adsorption of beta-glucosidases in two commercial preparations onto pretreated biomass and lignin. Biotechnology for Biofuels 2013, 6.

34. Rahikainen JL, Evans JD, Mikander S, Kalliola A, Puranen T, Tamminen T, Marjamaa K, Kruus K: Cellulase-lignin interactions-The role of carbohydratebinding module and pH in non-productive binding. Enzyme and Microbial Technology 2013, 53:315-321.

35. Rahikainen JL, Moilanen U, Nurmi-Rantala S, Lappas A, Koivula A, Viikari L, Kruus $\mathrm{K}$ : Effect of temperature on lignin-derived inhibition studied with three structurally different cellobiohydrolases. Bioresource Technology 2013, 146:118-125.

36. Wang H, Kobayashi S, Hiraide H, Cui ZJ, Mochidzuki K: The Effect of Nonenzymatic Protein on Lignocellulose Enzymatic Hydrolysis and Simultaneous Saccharification and Fermentation. Applied Biochemistry and Biotechnology 2015, 175:287-299.

37. Lou HM, Wang MX, Lai HR, Lin XL, Zhou MS, Yang DJ, Qiu XQ: Reducing nonproductive adsorption of cellulase and enhancing enzymatic hydrolysis of lignocelluloses by noncovalent modification of lignin with lignosulfonate. Bioresource Technology 2013, 146:478-484.

38. Wang ZJ, Zhu JY, Fu YJ, Qin MH, Shao ZY, Jiang JG, Yang F: Lignosulfonatemediated cellulase adsorption: enhanced enzymatic saccharification of lignocellulose through weakening nonproductive binding to lignin. Biotechnology for Biofuels 2013, 6. 
39. Newman $\mathrm{RH}$, Vaidya AA, Campion $\mathrm{SH}$ : A mathematical model for the inhibitory effects of lignin in enzymatic hydrolysis of lignocellulosics. Bioresource Technology 2013, 130:757-762.

40. Nimlos MR, Beckham GT, Matthews JF, Bu LT, Himmel ME, Crowley MF: Binding Preferences, Surface Attachment, Diffusivity, and Orientation of a Family 1 Carbohydrate-binding Module on Cellulose. Journal of Biological Chemistry 2012, 287:20603-20612.

41. Pellegrini VOA, Lei N, Kyasaram M, Olsen JP, Badino SF, Windahl MS, Colussi F, Cruys-Bagger N, Borch K, Westh P: Reversibility of Substrate Adsorption for the Cellulases Cel7A, Cel6A, and Cel7B from Hypocrea jecorina. Langmuir 2014, 30:12602-12609.

42. Jalak J, Valjamae P: Multi-Mode Binding of Cellobiohydrolase Cel7A from Trichoderma reesei to Cellulose. Plos One 2014, 9:9.

43. Reyes-Ortiz V, Heins RA, Cheng G, Kim EY, Vernon BC, Elandt RB, Adams PD, Sale KL, Hadi MZ, Simmons BA, et al.: Addition of a carbohydrate-binding module enhances cellulase penetration into cellulose substrates.

Biotechnology for Biofuels 2013, 6:13.

44. Payne CM, Resch MG, Chen LQ, Crowley MF, Himmel ME, Taylor LE, Sandgren M, Stahlberg J, Stals I, Tan ZP, et al.: Glycosylated linkers in multimodular lignocellulose-degrading enzymes dynamically bind to cellulose. Proceedings of the National Academy of Sciences of the United States of America 2013, 110:14646-14651.

45. Chen LQ, Drake MR, Resch MG, Greene ER, Himmel ME, Chaffey PK, Beckham GT, Tan ZP: Specificity of O-glycosylation in enhancing the stability and cellulose binding affinity of Family 1 carbohydrate-binding modules. Proceedings of the National Academy of Sciences of the United States of America 2014, 111:7612-7617.

46. Jalak J, Kurasin M, Teugjas H, Valjamae P: Endo-exo Synergism in Cellulose Hydrolysis Revisited. Journal of Biological Chemistry 2012, 287:28802-28815.

47. Wang JP, Quirk A, Lipkowski J, Dutcher JR, Clarke AJ: Direct in Situ Observation of Synergism between Cellulolytic Enzymes during the Biodegradation of Crystalline Cellulose Fibers. Langmuir 2013, 29:14997-15005.

48. Hu J, Arantes V, Pribowo A, Gourlay K, Saddler JN: Substrate factors that influence the synergistic interaction of AA9 and cellulases during the enzymatic hydrolysis of biomass. Energy \& Environmental Science 2014, 7:2308-2315.

49. Beeson WT, Vu VV, Span EA, Phillips CM, Marletta MA: Cellulose degradation by polysaccharide monooxygenases. Annu Rev Biochem 2015, 84:923-946.

50. Eibinger M, Ganner T, Bubner P, Rosker S, Kracher D, Haltrich D, Ludwig R, Plank H, Nidetzky B: Cellulose Surface Degradation by a Lytic Polysaccharide Monooxygenase and Its Effect on Cellulase Hydrolytic Efficiency. Journal of Biological Chemistry 2014, 289:35929-35938.

51. Agger JW, Isaksen T, Varnai A, Vidal-Melgosa S, Willats WGT, Ludwig R, Horn SJ, Eijsink VGH, Westereng B: Discovery of LPMO activity on hemicelluloses shows the importance of oxidative processes in plant cell wall degradation. 
Proceedings of the National Academy of Sciences of the United States of America 2014, 111:6287-6292.

52. Fontes CMGA, Gilbert HJ: Cellulosomes: Highly Efficient Nanomachines

Designed to Designed to Deconstruct Plant Cell Wall Complex

Carbohydrates. Annual Review of Biochemistry, Vol 79 2010, 79:655-681.

53. Harris PV, Xu F, Kreel NE, Kang C, Fukuyama S: New enzyme insights drive advances in commercial ethanol production. Current Opinion in Chemical Biology 2014, 19:162-170.

54. Ding SY, Liu YS, Zeng YN, Himmel ME, Baker JO, Bayer EA: How Does Plant Cell Wall Nanoscale Architecture Correlate with Enzymatic Digestibility? Science 2012, 338:1055-1060.

\section{Figure Captions}

Figure 1. Multi-scale imaging of plant cell wall deconstruction by thermochemical pretreatment and enzymatic hydrolysis. The range of scales and typical microscopy modalities used are indicated. 
Figure 2. Interference caused by lignin. Lignin (yellow bodies) has been hypothesized to inhibit cellulases (red) by physically decreasing accessibility to cellulose (green), by attracting enzymes to bind, and by direct competitive or non -competitively inhibiting small molecule lignin deconstruction products (i.e. vanillic acid, vanillin, catechol, coumeric acid, ferulic acid and caffeic acid). Recurrent evidence for each of these mechanisms suggests they may all play a role.

Figure 3. Illustration of cellulose deconstruction by free (red) and complexed (blue) enzyme systems. Free enzymes with single CBMs and catalytic units (Cel7A) hydrolyze cell wall polysaccharides by utilizing endoglucanases and CBHs to react with accessible cellulose surfaces. Complexed enzymes (cellulosomes) with multiple catalytic and binding specificities likely have lower off-rates and once bound at multiple points of contact disrupt the biomass surface resulting in an increase in surface area. Combining these two enzyme paradigms on fractionated biomass synergistically deconstructs the cell walls by increasing the reactive surface area allowing free enzymes to better diffuse and processively hydrolyze the substrate.

Figure 4. Illustration of how multiple enzymes employing different strategies can work synergistically to deconstruct biomass cell walls. Also, pretreatment that removes lignin and hemicellulose enhances the enzymatic activity enabling the benefits of combining these deconstruction mechanisms. 


\section{multiscals blomass deconetruction}

multiscols blomass deconstruction

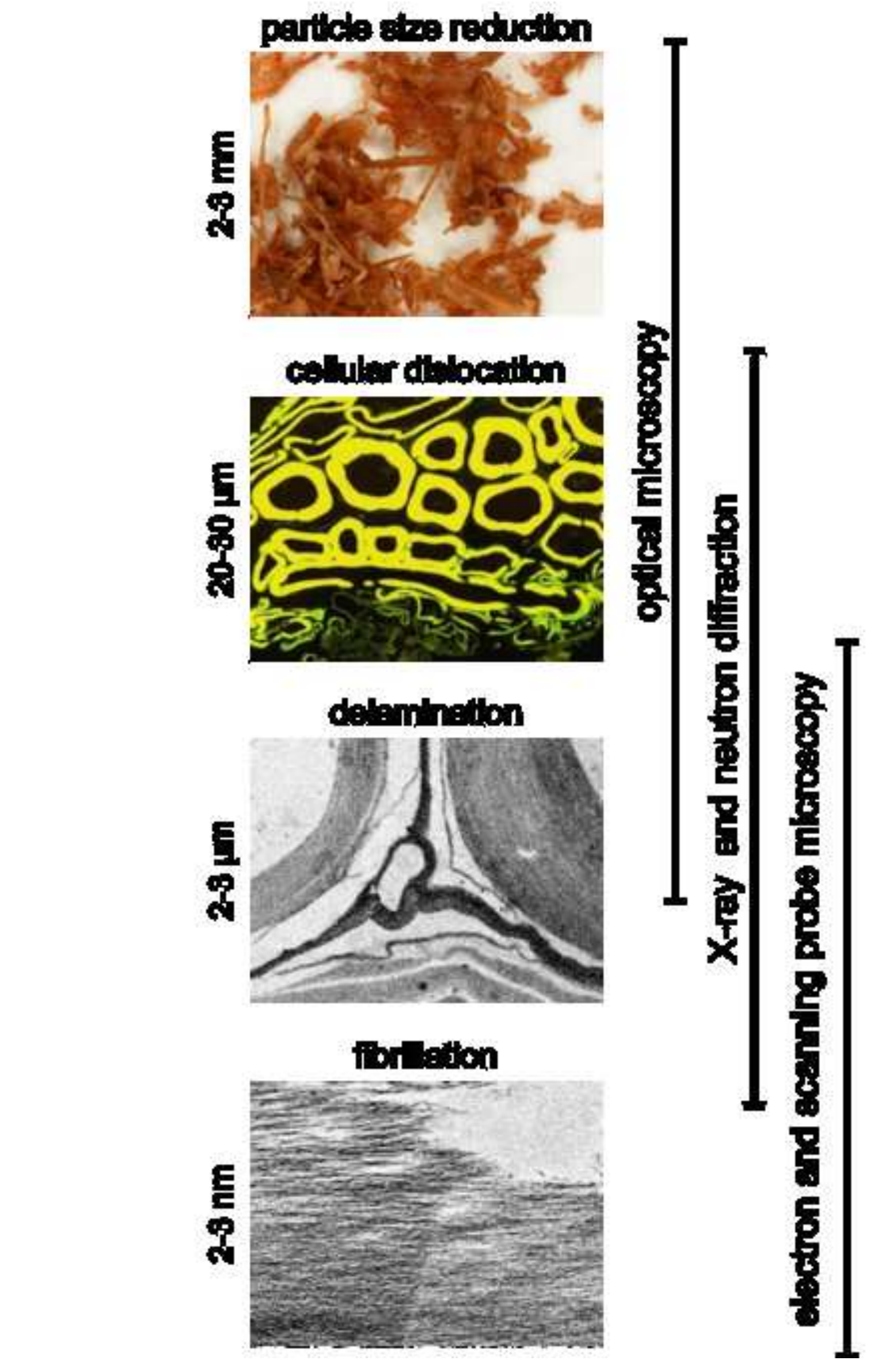

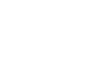

. 
physical steric hinderance

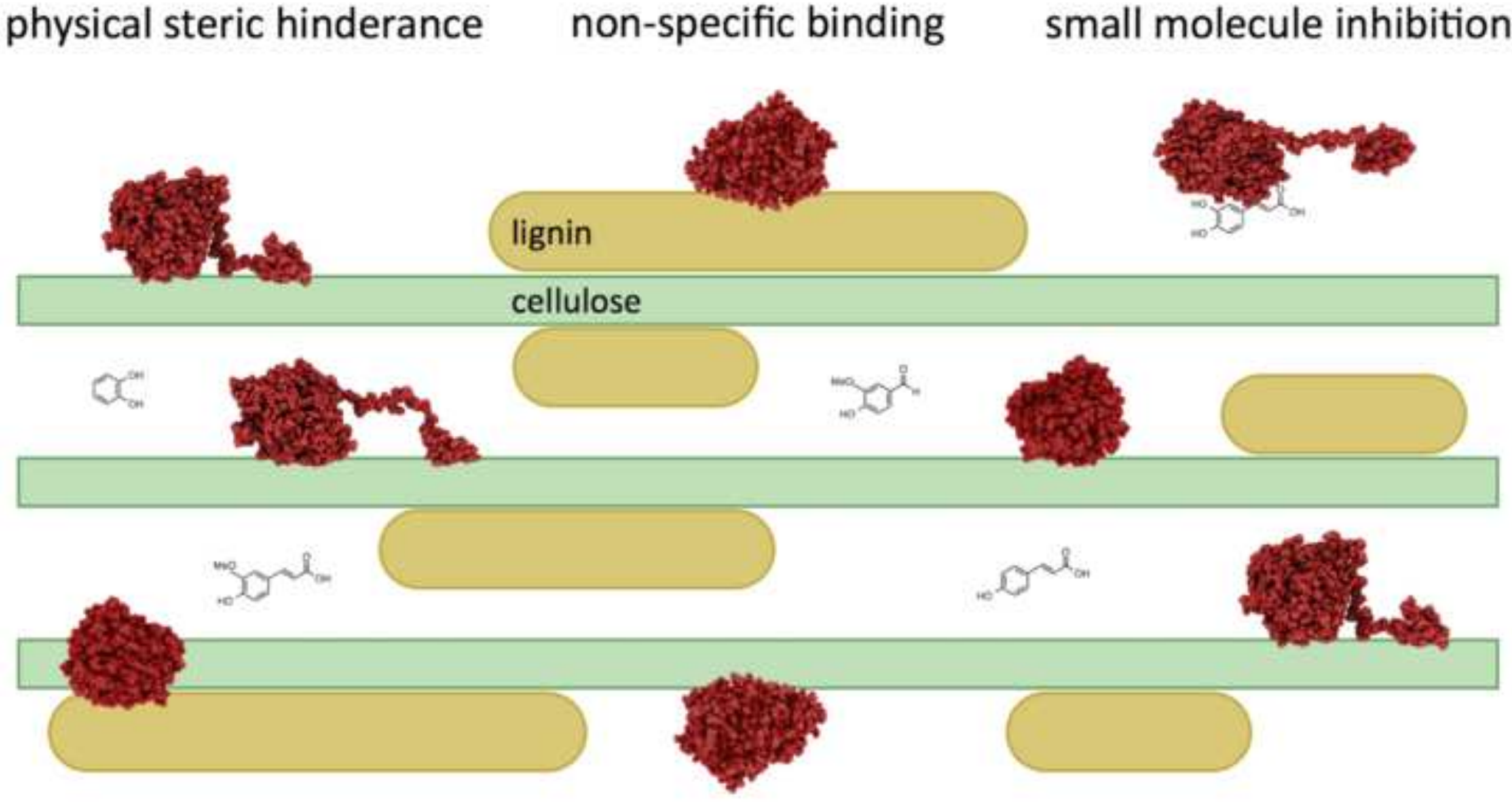



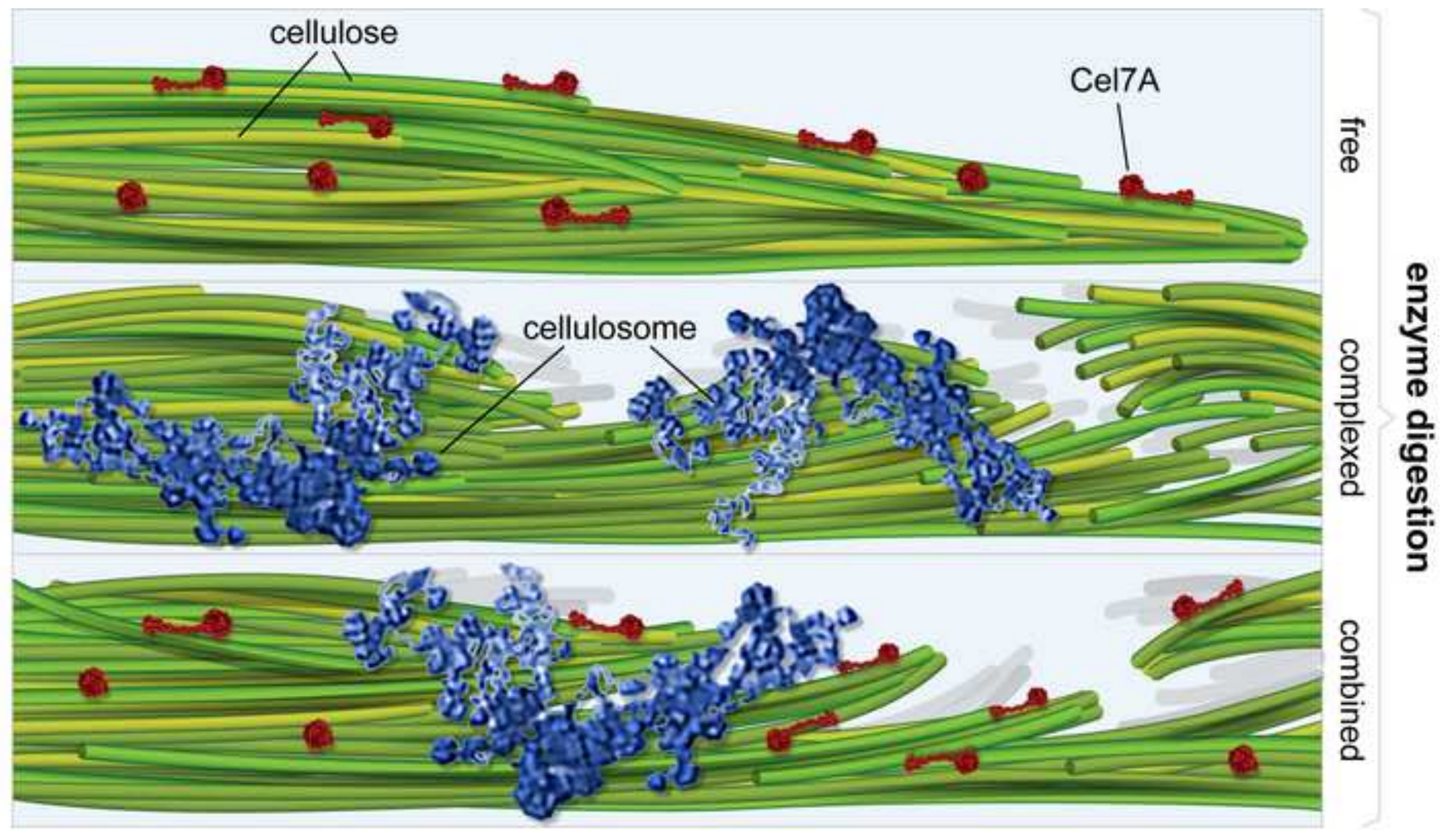

ᄋ̊

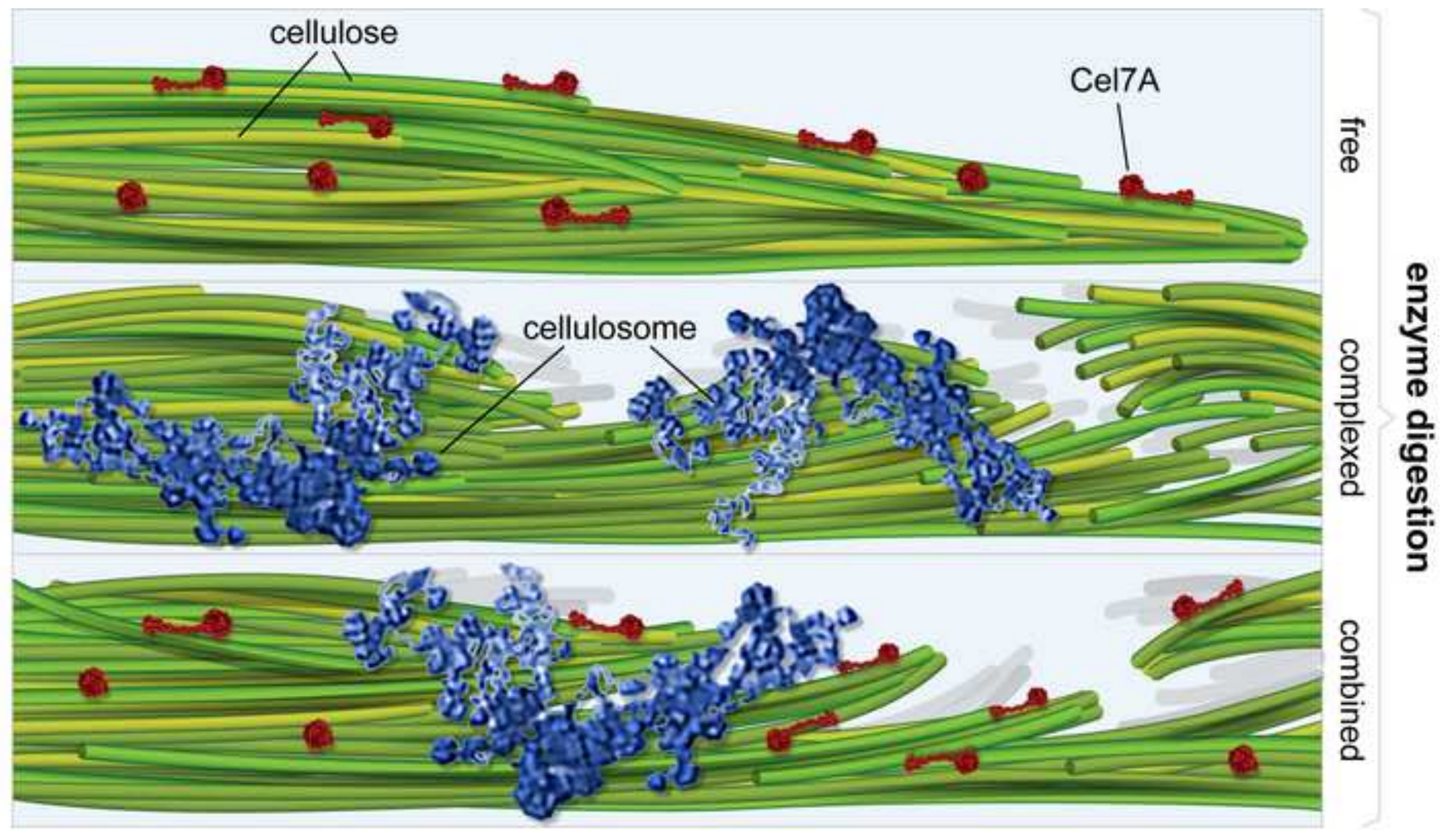

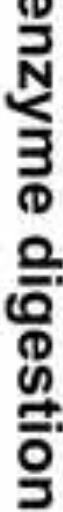




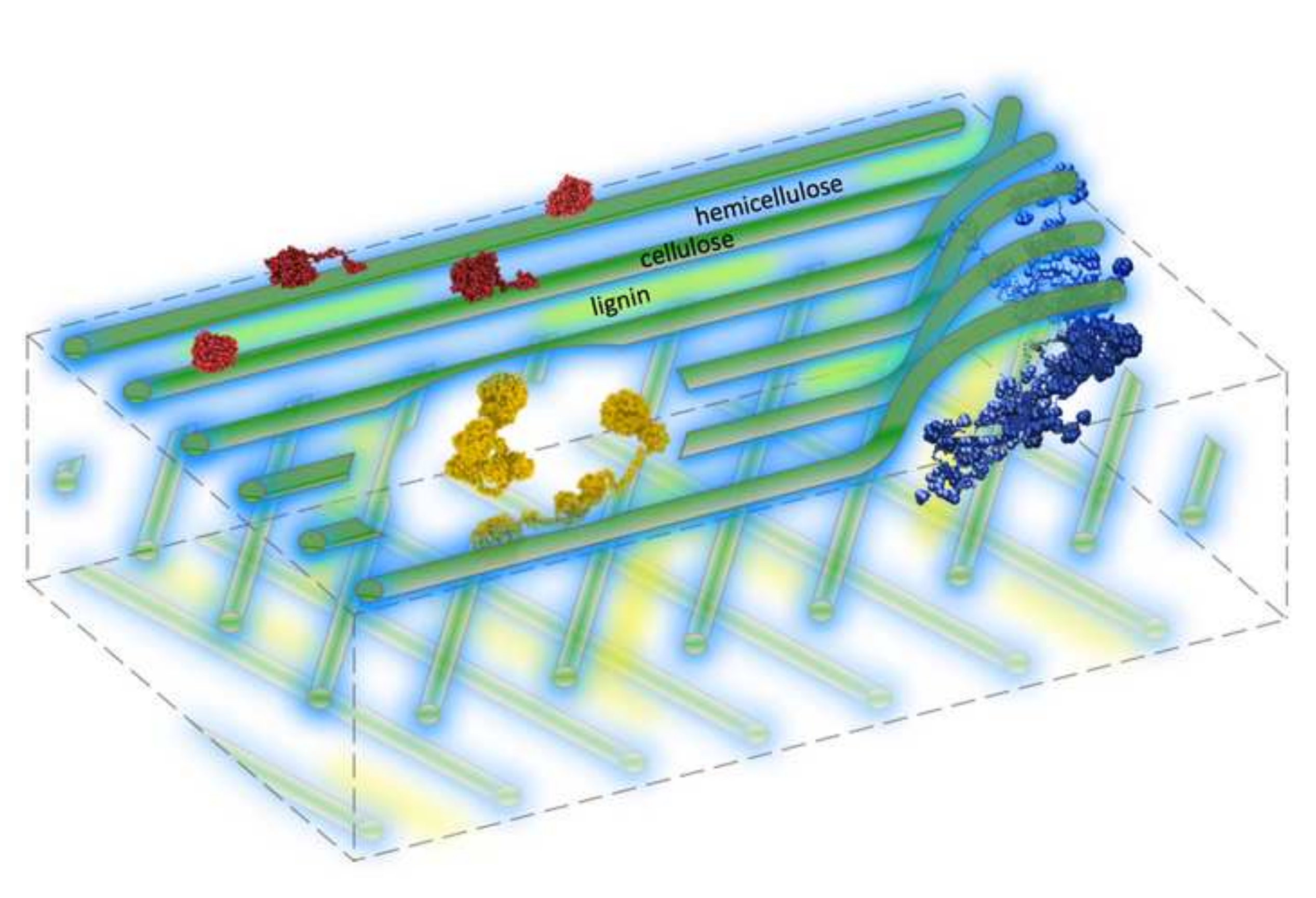

.
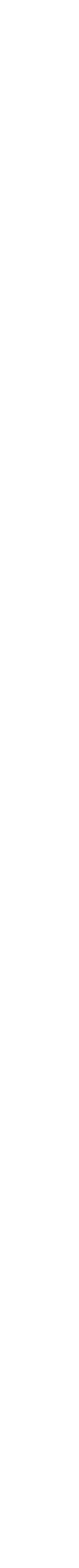